University of Nebraska - Lincoln

DigitalCommons@University of Nebraska - Lincoln

Roman L. Hruska U.S. Meat Animal Research

U.S. Department of Agriculture: Agricultural Center

Research Service, Lincoln, Nebraska

2006

\title{
Quantification of Calpastatin Using an Optical Surface Plasmon Resonance Biosensor
}

\author{
G. H. Geesink \\ CCL Research
}

J. G. P. van der Palen

CCL Research

M. P. Kent

USDA-ARS

E. Veiseth

USDA-ARS

\section{G. Hemke}

CCL Research, geert.geesink@ccl.nl

See next page for additional authors

Follow this and additional works at: https://digitalcommons.unl.edu/hruskareports

Geesink, G. H.; van der Palen, J. G. P.; Kent, M. P.; Veiseth, E.; Hemke, G.; and Koohmaraie, M., "Quantification of Calpastatin Using an Optical Surface Plasmon Resonance Biosensor" (2006). Roman L. Hruska U.S. Meat Animal Research Center. 234.

https://digitalcommons.unl.edu/hruskareports/234

This Article is brought to you for free and open access by the U.S. Department of Agriculture: Agricultural Research Service, Lincoln, Nebraska at DigitalCommons@University of Nebraska - Lincoln. It has been accepted for inclusion in Roman L. Hruska U.S. Meat Animal Research Center by an authorized administrator of DigitalCommons@University of Nebraska - Lincoln. 


\section{Authors}

G. H. Geesink, J. G. P. van der Palen, M. P. Kent, E. Veiseth, G. Hemke, and M. Koohmaraie 


\title{
Quantification of calpastatin using an optical surface plasmon resonance biosensor
}

\author{
G.H. Geesink ${ }^{\text {a,* }}$, J.G.P. van der Palen ${ }^{\text {a }}$, M.P. Kent ${ }^{b}$, E. Veiseth ${ }^{b}$, \\ G. Hemke ${ }^{a}$, M. Koohmaraie ${ }^{b}$ \\ ${ }^{a}$ CCL Research, PO Box 107, Veghel NL-5460 AC, The Netherlands \\ ${ }^{\mathrm{b}}$ Roman L. Hruska U.S. Meat Animal Research Center, ARS, USDA, Clay Center, NE 68933, USA
}

Received 28 January 2005; received in revised form 28 April 2005; accepted 28 April 2005

\begin{abstract}
An immunological biosensor for calpastatin was developed on a surface plasmon resonance based system (Biacore Q). The performance of the biosensor assay was evaluated using ovine and bovine muscle and heart extracts with known calpastatin activity. In addition, the relationship between immunologically detectable calpastatin at 1 day postmortem and shear force at 14 days postmortem was investigated for bovine longissimus dorsi. Calpastatin biosensor results for several experiments were linearly related to calpastatin activity measurements with correlation coefficients ranging from 0.51 to 0.99 . The intra- and inter-assay CVs were $<6 \%$ $(n=12)$. During postmortem storage, the amount of immunologically detectable calpastatin decreased faster than the inhibitory activity in the enzymatic assay. Probably, the epitope recognized by the antibody is degraded faster than the inhibitory sites of calpastatin during postmortem storage. Calpastatin content at 1 day postmortem was correlated to shear force at 14 days postmortem $(r=0.75)$. It is anticipated that developments in the near future will allow for at-line calpastatin determinations in beef plants. At present, the calpastatin biosensor assay appears suitable for research purposes where large numbers of samples need to be processed for breed evaluation or selection programs because this assay requires less labor than other methods.
\end{abstract}

(c) 2005 Elsevier Ltd. All rights reserved.

Keywords: Biosensor; Calpastatin; Tenderness

\section{Introduction}

There is a large body of evidence indicating that $\mu$ calpain is the major cause of postmortem tenderization of skeletal muscle through degradation of structural proteins (for reviews, see Geesink, Ilian, Morton, \& Bickerstaffe, 2000; Koohmaraie, 1996). The activity of $\mu$ calpain in postmortem muscle is controlled by calpastatin, its endogenous inhibitor. Postrigor calpastatin activity (1-2 days p.m.) accounts for a greater portion of the variation in tenderness of aged beef longissimus $(\sim 40 \%)$ than any other single measure (Shackelford et al., 1994; Whipple, Koohmaraie, Dikeman, \& Crouse, 1990). For

\footnotetext{
* Corresponding author. Tel.: +31 413 382633; fax: +31 413382141 .

E-mail address: geert.geesink@ccl.nl (G.H. Geesink).
}

this reason calpastatin quantification in skeletal muscle is commonly performed in research on meat tenderness.

Most frequently, calpastatin quantity, measured as $\mu$-calpain inhibitory activity, is performed on samples subjected to ion-exchange chromatography to separate calpastatin from the calpains (Koohmaraie, 1990). To facilitate quantification of a large number of samples in a breed evaluation program, muscle extracts were heated to $95^{\circ} \mathrm{C}$ instead of being subjected to chromatography, making use of the fact that calpastatin retains its activity under these conditions (Shackelford et al., 1994). Methods based on immunological quantification include an ELISA (Doumit, Lonergan, Arbona, Killefer, \& Koohmaraie, 1996) and Western blotting (Sensky et al., 1999). Although the ELISA method lends itself to 
automation, all of these methods are rather labor intensive and require at least several hours to complete.

An alternative to these methods is the use of a biosensor, which is a measurement system that uses biological ligands as a part of a biotransducer that transforms chemical information into an analytically useful signal. A number of recent publications have addressed the suitability of surface plasmon resonance (SPR) based biosensors for analyses in the meat industry. These include analysis of vitamin $B_{12}$ (Indyk et al., 2002), drug residues (Baxter, O'Connor, Haughey, Crooks, \& Elliot, 1999; Elliott, Baxter, Crooks, \& McCaughey, 1999), staphylococcal toxins (Nedelkov, Rasooly, \& Nelson, 2000; Rasooly \& Rasooly, 1999) B-agonists (Haughey et al., 2001) and serum antibodies against Salmonella (Jongerius-Gortemaker, Goverde, van Knapen, \& Bergwerff, 2002). From these studies it appears that SPR biosensors offer a valuable alternative to other techniques because it is both rapid and real-time.

The purpose of the present study was to explore the suitability of a SPR biosensor system (Biacore Q) for quantification of calpastatin.

\section{Material and methods}

\subsection{Samples}

Samples were obtained in three separate experiments. The Roman L. Hruska U.S. Meat Animal Research Center Animal Care and Use Committee approved the use of animals in the first two experiments. The animals were slaughtered humanely and dressed using typical procedures. Carcasses were chilled at $0^{\circ} \mathrm{C}$.

\subsubsection{Experiment 1}

Twelve sheep (12 months of age) were used. From five animals, a portion of the longissimus dorsi of one carcass side was dissected after dressing for determination of calpastatin activity. At 2 days p.m. the longissimus dorsi of the intact carcass side was dissected and a portion was removed for determination of calpastatin activity. After vacuum storage at $4{ }^{\circ} \mathrm{C}$, the remainder of the muscle was sampled for determination of calpastatin activity at 10 days p.m.

From all 12 animals the hearts were collected. Four of these were processed immediately for determination of calpastatin activity. The remaining hearts were vacuum packed and stored at $4{ }^{\circ} \mathrm{C}$. Four of these were sampled at 2 days p.m. and the remaining at 8 days p.m.

\subsubsection{Experiment 2}

From 30 steers (14-16 months of age), a portion of the longissimus of one carcass side was sampled at 2 days p.m. for determination of calpastatin activity.

\subsubsection{Experiment 3}

Thirty longissimus samples from female cattle (300$400 \mathrm{~kg}$ carcass weight) were obtained at 1 day p.m. from a commercial slaughterplant. The muscles were sampled at 1 day p.m. for determination of calpastatin activity. Samples were stored at $-80^{\circ} \mathrm{C}$ until quantification of calpastatin. The remainder of the muscle was vacuum packed and aged at $2{ }^{\circ} \mathrm{C}$ until 14 days p.m. After the aging period a $2 \mathrm{~cm}$ thick steak was vacuum packaged and stored at $-20^{\circ} \mathrm{C}$ for determination of the shear force.

\subsection{Preparation of samples for quantification of calpastatin}

Samples $(25 \mathrm{~g})$ were homogenized in three volumes of cold $50 \mathrm{mM}$ Tris (prerigor) or $100 \mathrm{mM}$ Tris (postrigor), $10 \mathrm{mM}$ EDTA, pH 8.3, containing $0.05 \%$ B-MCE, $100 \mathrm{mg} / 1$ ovomucoid, $2 \mathrm{mM}$ PMSF, and $6 \mathrm{mg} / 1$ leupeptin. The homogenates were centrifuged at $16,000 \mathrm{~g}$ for $2 \mathrm{~h}$ at $4{ }^{\circ} \mathrm{C}$. The supernatant was collected, heated to $95^{\circ} \mathrm{C}$ in a waterbath, and maintained at this temperature for $15 \mathrm{~min}$. Samples were chilled on ice and clarified by centrifugation at $37,500 \mathrm{~g}$ for $1 \mathrm{~h}$ at $4{ }^{\circ} \mathrm{C}$. The supernatants were dialyzed overnight against $40 \mathrm{mM}$ Tris, $5 \mathrm{mM}$ EDTA, $0.05 \%$ B-MCE, pH 7.35 at $4{ }^{\circ} \mathrm{C}$. Calpastatin activity of the heated extracts was determined as described by Koohmaraie (1990).

In Experiments 1 and 2, aliquots $(2 \mathrm{ml})$ of the extracts were frozen at $-80^{\circ} \mathrm{C}$ and shipped on dry ice to $\mathrm{CCL}$ research. Samples were stored at $-80^{\circ} \mathrm{C}$ until use. For the beef samples, aliquots were also collected before dialysis. Extracts from the third experiment were assayed directly for calpastatin content as described below.

\subsection{Preparation of the biosensor chip}

This assay was developed on a BIACORE Q biosensor system (Biacore, Uppsala, Sweden) controlled by a BIACORE Q Software package version 3.01.

Human erythrocyte calpastatin (Calbiochem, San Diego, CA) was used to coat the biosensor chip and for the calpastatin standard curve.

Prior to coating the CM5 biosensor chip (Biacore, Uppsala, Sweden), calpastatin was diluted to $40 \mu \mathrm{g} / \mathrm{ml}$ in $10 \mathrm{mM}$ sodium acetate, $\mathrm{pH}$ 4.0. The carboxymethylated dextran layer on the sensor chip surface was activated by derivatization with $N$-hydroxysuccinimide (NHS) mediated by $N$-ethyl- $N^{\prime}$-(3-diethylaminopropyl)carbodiimide (EDC) according to Fagerstam, Frostell-Karlsson, Karlsson, Persson, and Ronnberg (1992). Activation, coupling of calpastatin and blocking of reactive groups were performed at a flow rate of $10 \mu \mathrm{l} / \mathrm{min}$ and $25^{\circ} \mathrm{C}$. Activation was carried out through injection of $70 \mu 1200 \mathrm{mM}$ EDC, $50 \mathrm{mM}$ NHS. Covalent coupling of calpastatin was achieved through injection of $70 \mu \mathrm{l}$ of the calpastatin solution. Remaining dextran-conjugated NHS-esters were 
deactivated with $70 \mu \mathrm{l} 1 \mathrm{M}$ ethanolamine $\mathrm{pH}$ 8.5. Noncovalently bound proteins were washed from the surface with running buffer (HBS-EP: 0.01 M HEPES, $0.15 \mathrm{M}$ $\mathrm{NaCl}, 3 \mathrm{mM}$ EDTA, $0.005 \%$ surfactant P20, pH 7.4).

\subsection{Assay for quantification of calpastatin}

For this assay monoclonal anti-calpastatin antibody 3B9 was used (Doumit \& Koohmaraie, 1999). The antibody was purified from hybridoma cell supernatant using Immunopure ${ }^{\circledR}$ immobilized protein G (Pierce, Rockford, IL), according to the manufacturers instructions. The protein concentration of the purified antibody was $4.6 \mathrm{mg} / \mathrm{ml}$. Prior to use, the antibody was diluted 20fold with HBS-EP.

The heated muscle extracts were filtered over $0.45 \mu \mathrm{m}$ filters. Samples with a calpastatin content higher than covered by the standard curve were diluted with dialysis buffer. To all samples $0.3 \mathrm{~g} / \mathrm{l}$ carboxymethylated dextrane from a stock solution of $3 \mathrm{~g} / \mathrm{l}$ was added to prevent nonspecific interaction with the dextrane matrix of the chip. Subsequently, samples were transferred to 96-well microtitre plates and placed in the biosensor's autosampler compartment. For each series of 12 samples a standard curve of calpastatin $(0.05-2.0 \mu \mathrm{g} / \mathrm{ml})$ was included.

The system was operated at a flow rate of $20 \mu \mathrm{l} / \mathrm{min}$. Before injection of the sample, HBS-EP was passed through the flow cell for $200 \mathrm{~s}$. Prior to injection of the sample, the autosampler mixed one part of antibody solution with nine parts of sample. This mixture was passed through the flow cell for $120 \mathrm{~s}$, followed by HBS-EP during $80 \mathrm{~s}$. The chip surface was regenerated by injection of $8 \mathrm{mM} \mathrm{NaOH}$ for $120 \mathrm{~s}$. followed by HBS-EP during $20 \mathrm{~s}$. The difference in response $5 \mathrm{~s}$ before and $5 \mathrm{~s}$ after injection of the sample was recorded and expressed as $\mu \mathrm{g}$ calpastatin $/ \mathrm{ml}$ using the standard curve.

\subsection{Shear force}

Frozen vacuum packaged steaks were tempered for $48 \mathrm{~h}$ at $2^{\circ} \mathrm{C}$, cooked for $1 \mathrm{~h}$ in a waterbath heated at $75^{\circ} \mathrm{C}$ and chilled under running tapwater. From each sample 10 rectangular subsamples of $1 \mathrm{~cm}^{2}$ were cut parallel with the fibre direction. Shear force $\left(\mathrm{N} / \mathrm{cm}^{2}\right)$ was determined perpendicular to the fibre direction using a draw bench (Adamel Lhomargy DY 30; Division d'Instruments S.A., Paris, France) equipped with a triangular shearing blade. The average shear force of the 10 measurements per sample was reported.

\subsection{Statistical analysis}

Significance of correlation coefficients between parameters was determined with Pearson's test using the SAS statistical package.

\section{Results and discussion}

Results from the biosensor method correlated well with the activity measurements, but the intercept of the linear relationship did not pass through zero (Figs. 1 and 2). The reason for this is that the immunological detectable amount of calpastatin decreases faster during postmortem storage than the amount detectable in the enzymatic assay (Fig. 3). A similar observation, using Western blotting, was reported by Geesink and Koohmaraie (1999). The

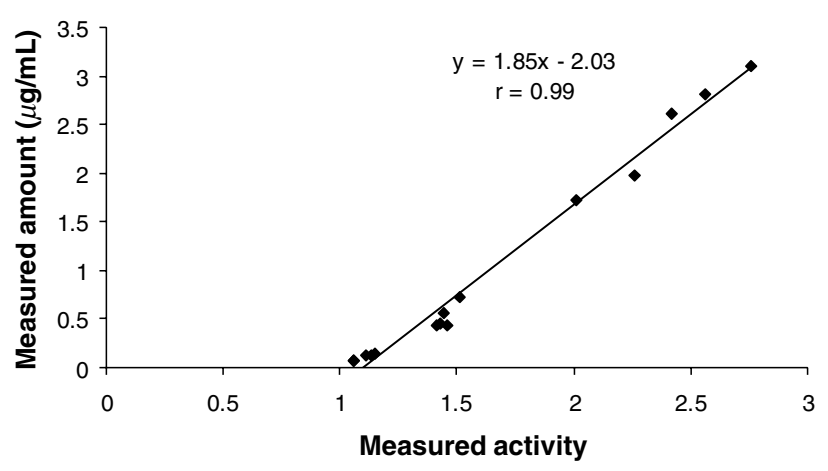

Fig. 1. The relation between the activity and immunologically detectable amount of calpastatin in ovine longissimus dorsi sampled at 0,2 and 10 days postmortem.

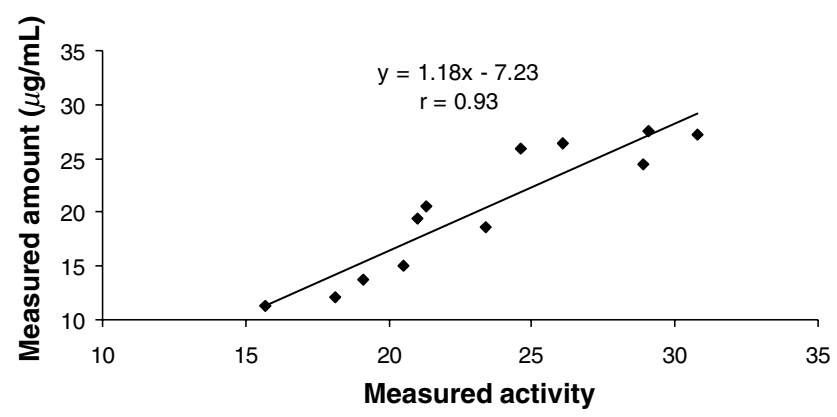

Fig. 2. The relation between the activity and immunologically detectable amount of calpastatin in ovine heart sampled at 0,2 and 10 days postmortem.

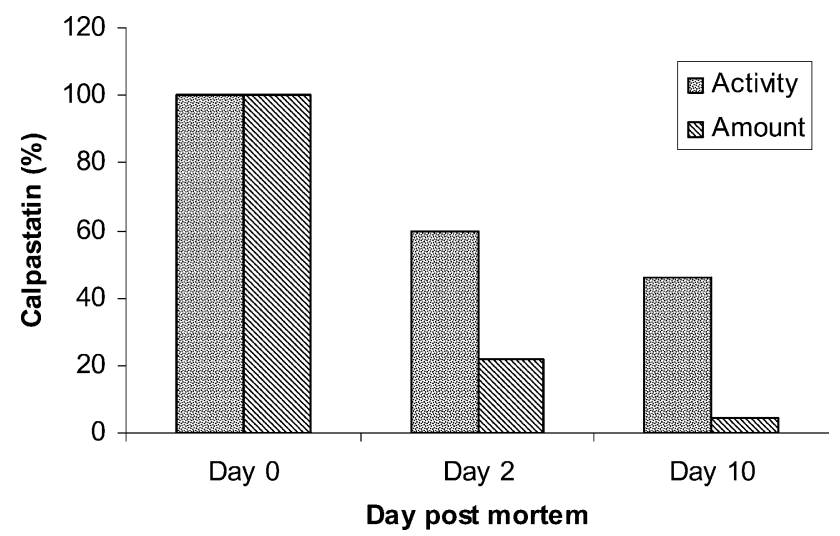

Fig. 3. Relative amount of calpastatin in ovine muscle at 0,2 and 10 days postmortem as determined by activity measurements or immunological detection. 
explanation for this is that calpastatin is degraded postmortem, but some proteolytic fragments retain their inhibitory activity (Doumit \& Koohmaraie, 1999; Imajoh et al., 1984; Mellgren \& Carr, 1983). Thus, the epitope recognized by the antibody is degraded faster than the inhibitory sites of calpastatin. As a consequence, the biosensor assay is not suitable to study the evolution in calpastatin activity during postmortem storage of muscle.

Since postrigor and not prerigor calpastatin activity is related to tenderness of aged longissimus dorsi (Whipple et al., 1990) the calpastatin activity was determined in 30 beef muscle extracts ( 2 days p.m.) and they were shipped to CCL. The calpastatin biosensor results showed a significant correlation $(p<0.01)$ with the activity measurements for the beef muscle extracts (Fig. 4).

The procedure to produce the extracts includes a dialysis step. Omission of this step would save a considerable amount of time and labor. To test whether this step can be omitted without a detrimental effect on the results, samples of the beef extracts were taken before and after dialysis. Omission of dialysis resulted in a decreased response in the biosensor assay with a mean value of $0.42 \mu \mathrm{g} / \mathrm{ml}$. However, the correlation with the measurements on the dialyzed samples was good $(r=0.82$; data not shown), and correlation with the activity measurements improved (Fig. 5). Thus, the dialysis step can be omitted from the extraction procedure without a detrimental effect on the results.

As mentioned earlier, samples with a calpastatin content above $2 \mu \mathrm{g} / \mathrm{ml}$ were diluted with dialysis buffer. The effect of sample dilution on the measurement was tested (Fig. 6). The results indicate that dilution has little on the measurements.

In the third experiment, we tested whether postrigor calpastatin content, as determined using the biosensor assay, is related to the shear force of aged beef. In agreement with the results of Whipple et al. (1990), postrigor calpastatin content was significantly correlated $(p<0.01)$ to the shear force of aged longissimus dorsi (Fig. 7).

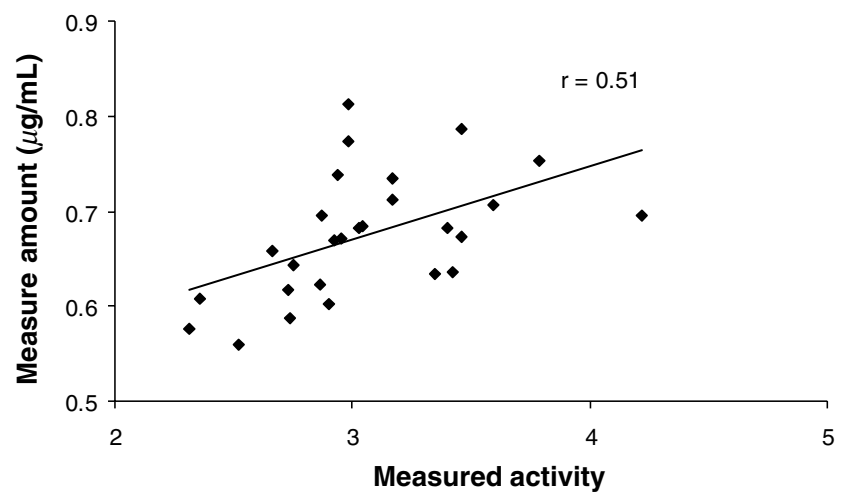

Fig. 4. The relationship between the activity and immunologically detectable amount of calpastatin in bovine longissimus dorsi sampled at 2 days p.m.

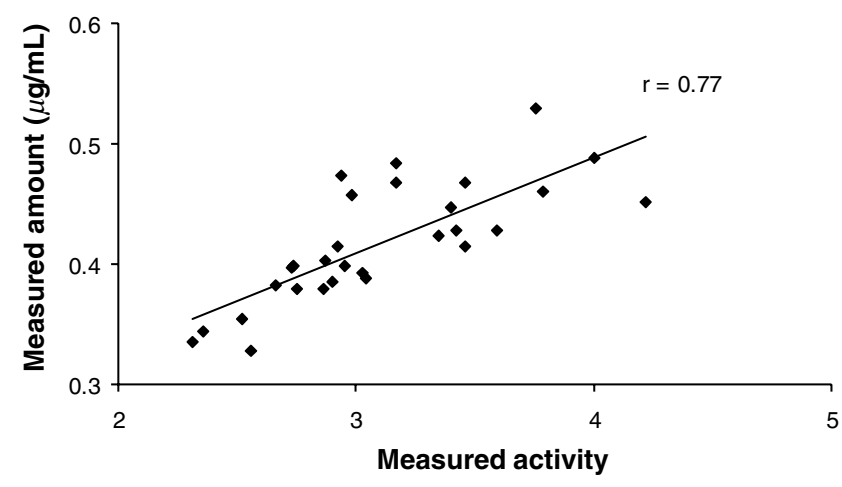

Fig. 5. The relationship between the activity and immunologically detectable amount of calpastatin in bovine longissimus dorsi sampled at 2 days p.m. Dialysis of the muscle extracts was omitted for these samples.

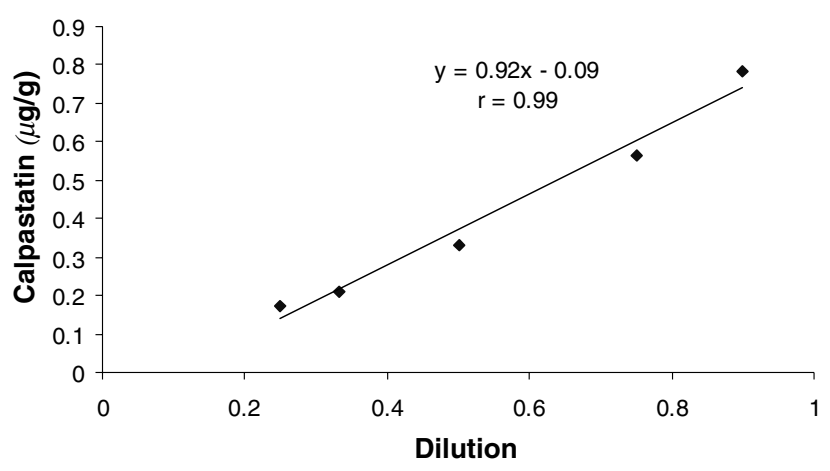

Fig. 6. The effect of sample dilution on the measurements.

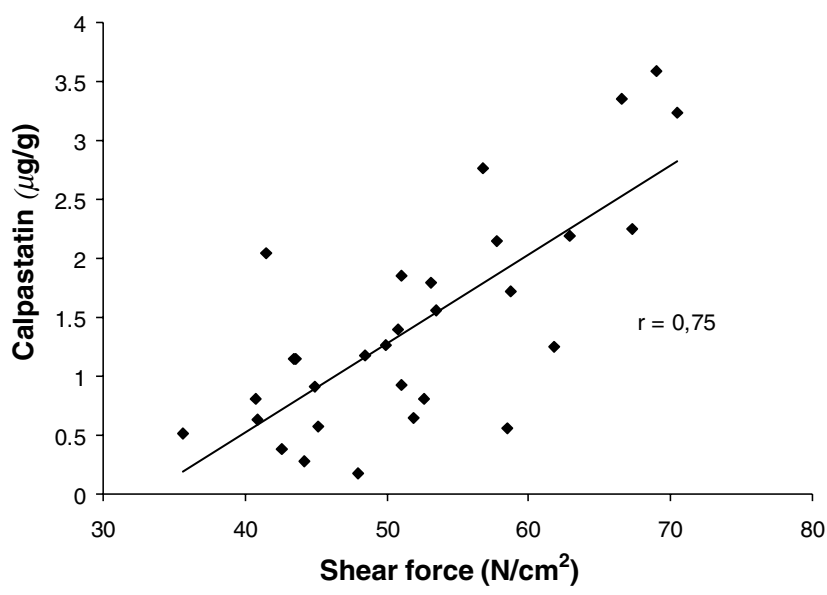

Fig. 7. The relationship between the immunologically detectable amount of calpastatin at 1 day p.m. and shear force at 14 days p.m. of bovine longissimus dorsi.

The Biacore Q system contains four flow channels, allowing for the sequential analysis of four different compounds in a single sample. The stability of the chip surface has not been fully tested, but we have performed more than 700 assays using a single flow channel. Thus one chip should allow for the measurement of at least 2800 samples, including standard curves. 
The repeatability and reproducibility were tested on 12 beef samples which were measured in duplicate on different dates. The mean intra-assay CVs were $3.2 \%$ and $5.6 \%$ on the different dates. The mean inter-assay $\mathrm{CV}$ was $5.8 \%$. This performance is similar to the ELISA for calpastatin developed by Doumit et al. (1996). In comparison, the ELISA showed a stronger correlation with activity measurements than the biosensor assay. The correlation between activity measurements and biosensor measurements can probably be improved by using the same polyclonal antibodies as used in the ELISA. Another important difference between the ELISA and biosensor assays is that with the ELISA a large number of samples can be processed simultaneously whereas the biosensor assay processes them sequentially. However, Biacore has developed a parallel 8-channel system and array systems are in development. With this development, high-throughput applications appear possible in the near future. One of these possibilities would be on-line screening for calpastatin content as a predictor of beef tenderness. Given the fact that the sample preparation procedure is simple (extraction, heating, clarification), it should also lend itself to automation with sufficient speed to process the number of samples generated at production speed in beef plants. At present, the calpastatin biosensor assay appears suitable for research purposes where large numbers of samples need to be processed for breed evaluation or selection programs.

\section{References}

Baxter, G. A., O'Connor, M. C., Haughey, S. A., Crooks, S. R., \& Elliot, C. T. (1999). Evaluation of an immunobiosensor for the on-site testing of veterinary drug residues at an abbatoir. Screening for sulfamethazine in pigs. Analyst, 124, 1315-1318.

Doumit, M. E., \& Koohmaraie, M. (1999). Immunoblot analysis of calpastatin degradation: Evidence for cleavage by calpain in postmortem muscle. Journal of Animal Science, 77, 1473-1476.

Doumit, M. E., Lonergan, S. M., Arbona, J. R., Killefer, J., \& Koohmaraie, M. (1996). Development of an enzyme-linked immunosorbent assay (ELISA) for quantification of skeletal muscle calpastatin. Journal of Animal Science, 74, 2679-2686.

Elliott, C. T., Baxter, G. A., Crooks, S. R. H., \& McCaughey, W. J. (1999). The development of a rapid immunobiosensor screening method for the detection of residues of sulphadiazine. Food and Agricultural Immunology, 11, 19-27.

Fagerstam, L. G., Frostell-Karlsson, A., Karlsson, R., Persson, B., \& Ronnberg, I. (1992). Biospecific interaction analysis using surface plasmon resonance detection applied to kinetic, binding site and concentration analysis. Journal of Chromatography, 597, 397-410.

Geesink, G. H., \& Koohmaraie, M. (1999). Postmortem proteolysis and calpain/calpastatin activity in callipyge and normal lamb biceps femoris during extended postmortem storage. Journal of Animal Science, 77, 1490-1501.

Geesink, G. H., Ilian, M. A., Morton, J. D., \& Bickerstaffe, R. (2000). Involvement of calpains in postmortem tenderisation. A review of recent research. Proceedings of the New Zealand Society of Animal Production, 60, 99-102.

Haughey, S. A., Baxter, G. A., Elliott, C. T., Persson, B., Jonson, C., \& Bjurling, P. (2001). Determination of clenbuterol residues in bovine urine by optical immunobiosensor assay. Journal of the Association of Analytical Communities International, 84, 1025-1030.

Imajoh, S., Kawasaki, H., Kisaragi, M., Mukai, M., Sugita, H., \& Suzuki, K. (1984). A 107-kDa inhibitor for calcium-activated neatral protease (CANP): Purification from the human liver. Journal of Biochemistry, 98, 757-765.

Indyk, H. E., Persson, B. S., Caselunghe, M. C., Moberg, A., Filonzi, E. L., \& Woollard, D. C. (2002). Determination of vitamin B12 in milk products and selected foods by optical biosensor protein binding assay: Method comparison. Journal of the Association of Analytical Communities International, 85, 72-81.

Jongerius-Gortemaker, B. G. M., Goverde, R. L. J., van Knapen, F., \& Bergwerff, A. A. (2002). Surface plasmon resonance (BIACORE) detection of serum antibodies against Salmonella enteritidis and Salmonella typhimurium. Journal of Immunological Methods, 266, 33-44.

Koohmaraie, M. (1990). Quantification of $\mathrm{Ca}^{2+}$-dependent protease activities by hydrophobic and ion-exchange chromatography. Journal of Animal Science, 68, 659-665.

Koohmaraie, M. (1996). Biochemical factors regulating the toughening and tenderizing process of meat. Meat Science, 43, 934-942.

Mellgren, R. L., \& Carr, T. C. (1983). The protein inhibitor of calcium dependent proteases: Purification from bovine heart and possible mechanisms of regulation. Archives of Biochemistry and Biophysics, 2, 779-786.

Nedelkov, D. A., Rasooly, A., \& Nelson, R. W. (2000). Multitoxin biosensor-mass spectrometry analysis: A new approach for rapid, realtime, sensitive analysis of staphylococcal toxins in food. International Journal of Food Microbiology, 60, 1-13.

Rasooly, L., \& Rasooly, A. (1999). Real time biosensor analysis of staphylococcal enterotoxin A in food. International Journal of Food Microbiology, 49, 119-127.

Sensky, P. L., Parr, T., Lockey, A. K., Bardsley, R. G., Buttery, P. J., Wood, J. D., et al. (1999). Altered calpain levels in longissimus muscle from normal pigs and heterozygotes with the ryanodine receptor mutation. Journal of Animal Science, 77, 2956-2964.

Shackelford, S. D., Koohmaraie, M., Cindiff, L. V., Gregory, K. E., Rohrer, G. A., \& Savell, J. W. (1994). Heritabilities and phenotypic and genetic correlations for bovine postrigor calpastatin activity, intramuscular fat content, Warner-Bratzler shear force, retail product yield, and growth rate. Journal of Animal Science, 72, 857-863.

Whipple, G., Koohmaraie, M., Dikeman, M. E., \& Crouse, J. D. (1990). Predicting beef-longissimus tenderness from various biochemical and histological muscle traits. Journal of Animal Science, 68, 4193-4199. 